\title{
Venous circulation of the human cardiac conduction
}

\section{system}

\author{
O. ELISKKA AND M. ELIŠKOVÁ \\ From the Department of Anatomy, Faculty of Medicine, Prague 2, U nemocnice 3, Czechoslovakia
}

SUMMARY The venous bed of the sinuatrial node in 25 human hearts and the atrioventricular conduction system in 50 human hearts were investigated after injection into different veins of the heart. Blood is drained from the sinuatrial node in two directions; that from the intermediate and upper parts of the node blood is directed upwards, draining into the junctional area of the superior vena cava with the right atrium. From the intermediate and the lower parts of the node the venous return is directed downwards, draining directly into the right atrium between the musculi pectinati.

The venous return from the ventricular conduction system is drained by three routes. The main route from the atrioventricular node and the atrioventricular bundle passes into the thebesian vein, which opened in 78 per cent of the cases studied into the right atrium next to the coronary sinus. The other route from the node and bundle is via a vein which accompanies the atrioventricular nodal artery, draining eventually into the middle cardiac vein. The third route takes venous blood from the lower part of the atrioventricular bundle and is drained to the tributaries of the great cardiac vein, interconnecting with the branches of the above two veins. The venous return from the ventricular bundle-branches is drained into the oblique septal veins.

The venous drainage of the conduction system was described by Geraudel (1928), Ábrahám (1964), and Kennel and Titus (1972), all of whom thought that blood was drained from the atrioventricular node by thebesian veins into the right ventricle. Truex and Schwartz (1951) also described the veins of the atrioventricular conduction system, but they regarded them as dilated sinusoids and maintained that they played an important role in facilitating the influence of toxins upon the conduction system.

In the present paper an attempt will be made to supplement and enlarge the data concerning the localisation of venous drainage of different segments of the conduction system and their interconnections.

\section{Subjects and methods}

The venous drainage of the sinuatrial node has been visualised in 25 human hearts (13 men, 12 women) by injecting the thebesian veins opening into the superior vena cava in the region of the node and opening between the musculi pectinati of the right atrium. The veins draining the region of the atrioventricular node and atrioventricular bundle have been visualised in 50 hearts $(27 \mathrm{men}, 23$ women) by injecting various veins, namely those

Received for publication 9 May 1979 opening into the upper part of the great cardiac vein, those opening into the upper part of middle cardiac vein, and, finally, by injecting thebesian veins opening into the right atrium. The substances used for injection included a solution of Indian ink in 2 per cent gelatin, a pigment Seabondorange suspension in 2 per cent gelatin, and a radiopaque substance, Mikropaque.

The regions of the sinuatrial nodes obtained from 16 hearts and those of the antrioventricular nodes and atrioventricular bundles obtained from 25 hearts were processed for histological examination by serial sectioning. The sinuatrial nodes were cut transversely and longitudinally; the atrioventricular nodes and bundles were sectioned transversely. The sections were stained with a trichrome stain utilising a blue counterstain, haematoxylin and eosin, and Weigert's iron haematoxylin.

The rest of the hearts were evaluated by dissection under a dissecting microscope after hydydration and clearing in methylsalicylate or in glycerin. Those injected with Micropaque were evaluated with the aid of $x$-ray films.

All the hearts were obtained from the Faculty Department of Forensic Medicine. The age range was 10 to $\mathbf{7 0}$ years. None of the patients from whom the hearts were obtained was reported to have had a history of heart disease. 


\section{Observations}

\section{SINUATRIAL NODE}

The sinuatrial node is drained (Fig. 1) by one to three small veins, 150 to $500 \mu \mathrm{m}$ in diameter which perforate the wall of the superior vena cava and open at its anterior circumference just above the junction of the vein with the right atrium. The

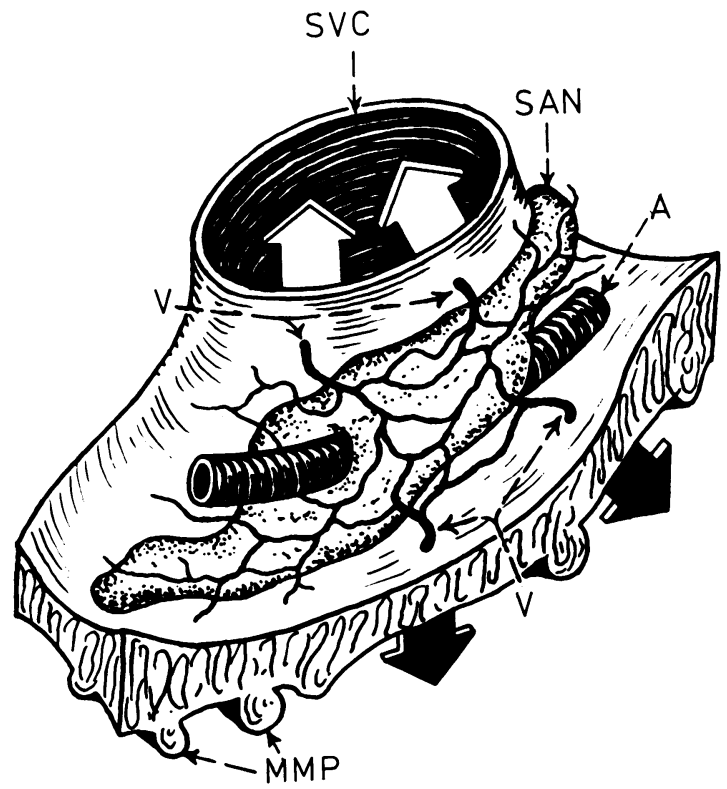

Fig. 1 Venous drainage of the sinuatrial node: the upper and the intermediate part of the node ( $S A N)$ drains into the superior vena cava (SVC-white arrows), the intermediate and the lower part of the node drains into the atrial appendage, the openings being placed between the musculi pectinati ( $M M P$-black arrows). $A$, sinuatrial node artery; $V$, veins draining the sinuatrial node. openings are irregularly distributed along the whole anterosuperior circumference of the superior vena cava. The draining veins originate from the plexiform network of postcapillary venules, 10 to $30 \mu \mathrm{m}$ in diameter, which fuse to form venules 50 to 150 $\mu \mathrm{m}$ thick. The injected specimens show (Fig. 2) that such veins collect together from the upper and the intermediate parts of the sinuatrial node to anastomose with similar veins draining its lower part, opening by two to three openings between the trabeculae in the crest of the auricular appendage. The two draining systems are extensively interconnected and no distinct borderline separating one from the other could be recognised.

The preparations disclose that most of the larger venules draining blood from the sinuatrial node pass parallel to the long axis of the node (Fig. 2).

Adequately injected specimens reveal that the ratio of postcapillary veins to fibres of the conduction system is $1: 1$ or $1: 2$. The initial segments of postcapillary veins passing between the fibres of the conduction system have their walls closely attached to those fibres (Fig. 3). We did not find any vein which, by virtue of either its size or position, could have been considered as a venous channel accompanying the large central artery of the sinuatrial node. Only small venules were found in the vicinity of the adventitia of that artery. Larger veins were found only beyond the boundaries of the node (Fig. 4).

\section{ATRIOVENTRICULAR NODE,} ATRIOVENTRICULAR BUNDLE, AND VENTRICULAR BUNDLE-BRANCHES

The injection methods enabled us to visualise several venous pathways draining the atrioventricular node (Fig. 5). The main draining vein is a thebesian vein, 0.5 to $2 \mathrm{~mm}$ thick, buried in the

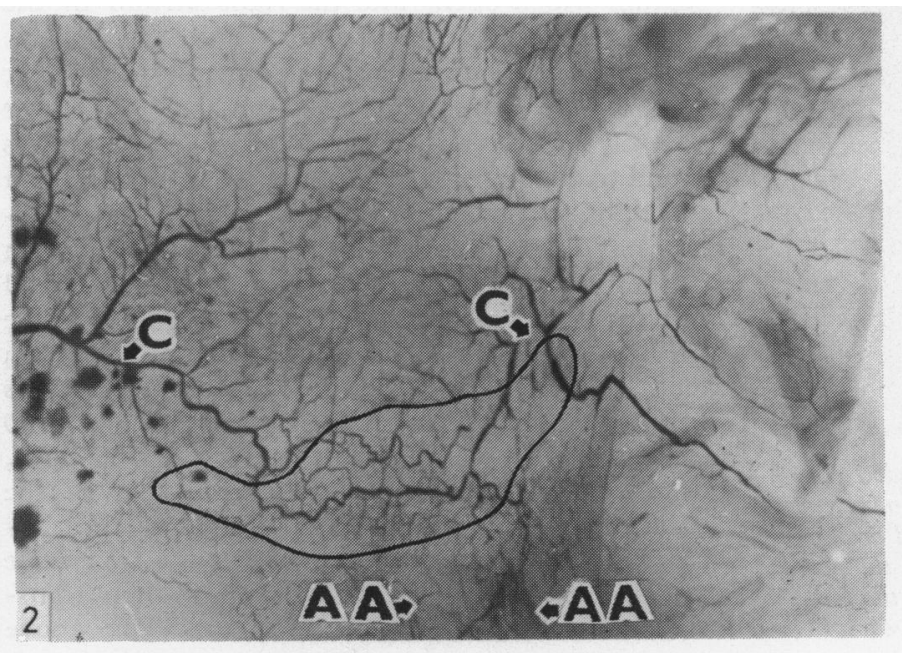

Fig. 2 The network of injected veins (Mikropaque) draining the $S A$ node into the superior vena cava $(C)$ and the right atrial appendage ( $A A)$. Cleared in methylsalicylate. Man aged 37 years. Plotted in the figure is the projection of the $S A$ node. 


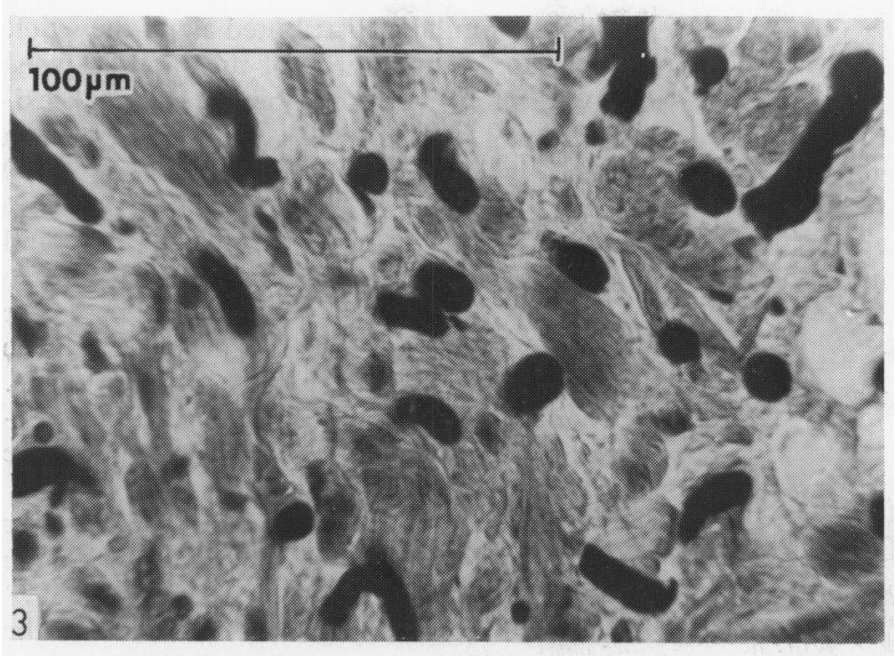

Fig. 3 The capillary segment of venules passing either transversely or obliquely between the fibres of the sinuatrial node. Blue trichrome stain, injection with gelatine-solved Indian ink. Man aged 38 years.

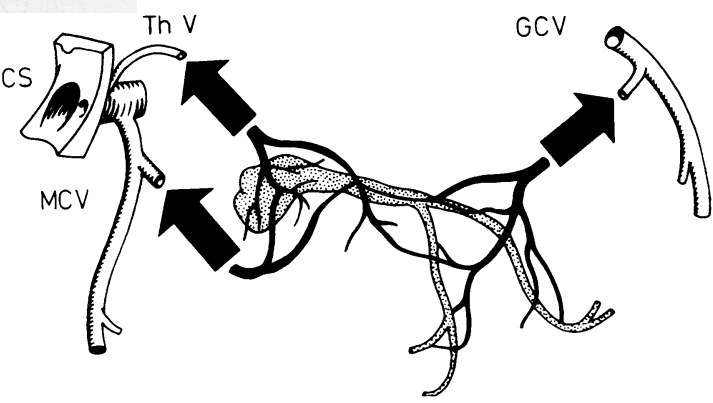

Fig. 5 Venous drainage of the ventricular conduction system. The black arrows indicate the venous drainage from the atrioventricular ( $A V$ ) node, the $A V$ bundle, and the branches into the veins of the great cardiac vein $(G C V)$, into the middle cardiac vein $(M C V)$, and into the right atrium in the vicinity of coronary sinus (CS) through a thebesian vein (Th V).

septum which opens into the right atrium in the vicinity of the coronary sinus. The vein collects blood from the upper part of the interventricular septum, the membranous septum, and the lower part of the interatrial septum. In 39 cases it was found to communicate by one or two openings with the right atrium, entering the atrium up to a distance of $1 \mathrm{~cm}$ anteriorly or posteriorly to the ostium of the coronary sinus. In eight instances it opened into the coronary sinus and in three into the middle cardiac vein. The trunk of the vein, 0.5 to $1 \mathrm{~cm}$ long, can be seen under the endocardium and its tributaries, three to seven in number and 50 to 300 $\mu \mathrm{m}$ thick, pass along on the surface of the node, occasionally extending into the substance of the node. They are parallel to its long axis, but occasionally they are diagonal so that the transverse sections through the node may show their transverse or oblique sections (Fig. 6). The above

Fig. 4 Transverse section through the $S A$ node. The vessels have been injected with gelatin-solved Indian ink. Most of the vessels appear to be cross-sectioned or on oblique section. In the upper and lower part of the node are wide draining veins $(V)$. $A$, the artery of the $S A$ node. Haematoxylin and eosin. Man aged 38 years. 


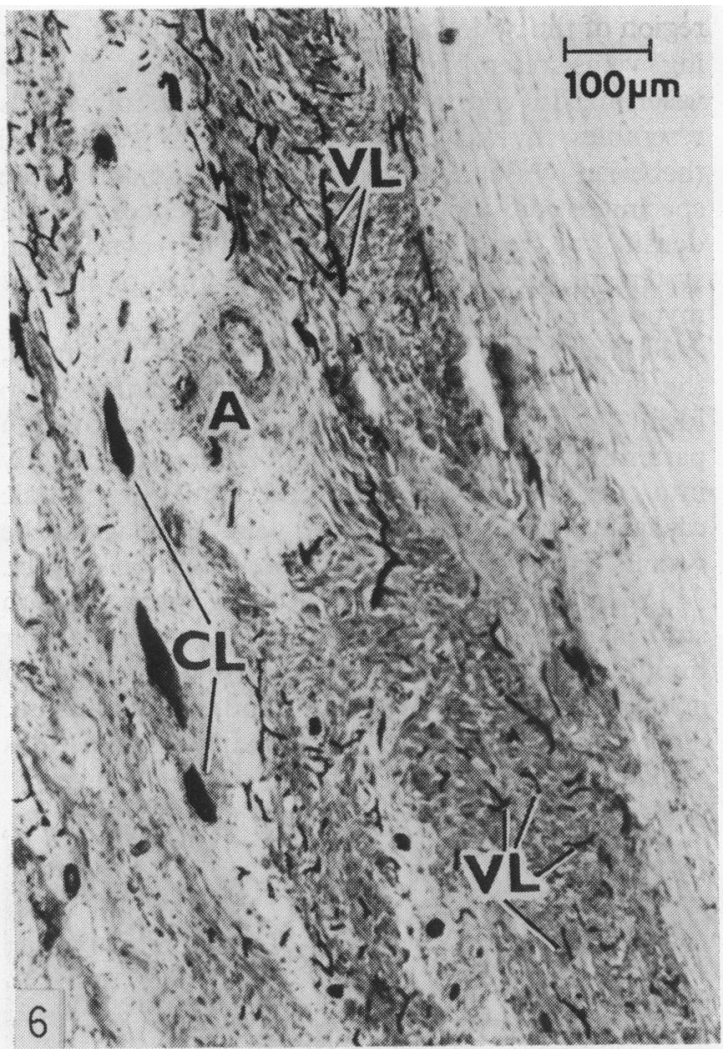

Fig. 6 The veins of an AV node (gelatin-solved Indian ink). The node shows networks of small venules $(V L)$. There are larger collecting venules (CL) at the margin of the node. $A$, artery of the $A V$ node. Blue trichrome stain. Man aged 64 years.

branches receive small venules and venous postcapillaries, 10 to $30 \mu \mathrm{m}$ thick, which interweave with the fibres of the atrioventricular node itself. The ratio appears to be one postcapillary venule to one to three conduction fibres. The other pathway of venous drainage from the node is a vein, 0.4 to $1 \mathrm{~mm}$ thick, which collects blood from the posterior and the intermediate part of the node and the adjacent areas of the septum. The vein passes along through the atrioventricular sulcus made up of loose connective tissue beneath the coronary sinus and opens into the middle cardiac vein (Fig. 5) at its junction with the coronary sinus. If the small cardiac vein is well developed, the vein may open into it. The vein passes along with the artery of the atrioventricular node, or may take a separate course several millimetres distant from this artery. The two draining veins have an extensive communicating anastomotic network. The branches of the septal vein draining blood from the atrioventricular node not only pass through the node but they proceed further, running through the atrioventricular bundle to communicate with the veins of the right and left bundle-branches. The majority of vessels, 15 to $30 \mu \mathrm{m}$ thick, are parallel to the fibres of the conduction system (Fig. 7 and 8). In the lower part of the atrioventricular bundle they show smooth transitions into the septal veins which drain anteriorly into the upper part of the great cardiac vein and posteriorly into the middle cardiac vein. The injection from the septal thebesian vein is capable of filling the veins opening into the great cardiac vein. Similarly, an injection into the great cardiac vein will fill the main branches of the septal thebesian vein. The postcapillary venules of the right and left bundle-branches run parallel with the fibres of the bundle-branches themselves (Fig. 9 and 10). The upper part of the bundle-branches is drained by both veins of wide calibre ( 50 to $80 \mu \mathrm{m}$ ) and of narrow calibre, whereas the lower part is drained only by narrow veins ( 10 to $20 \mu \mathrm{m}$ ). A more satisfactory injection of the venules was achieved in areas of the conduction system remote from the septal endocardium. The veins of the bundle-

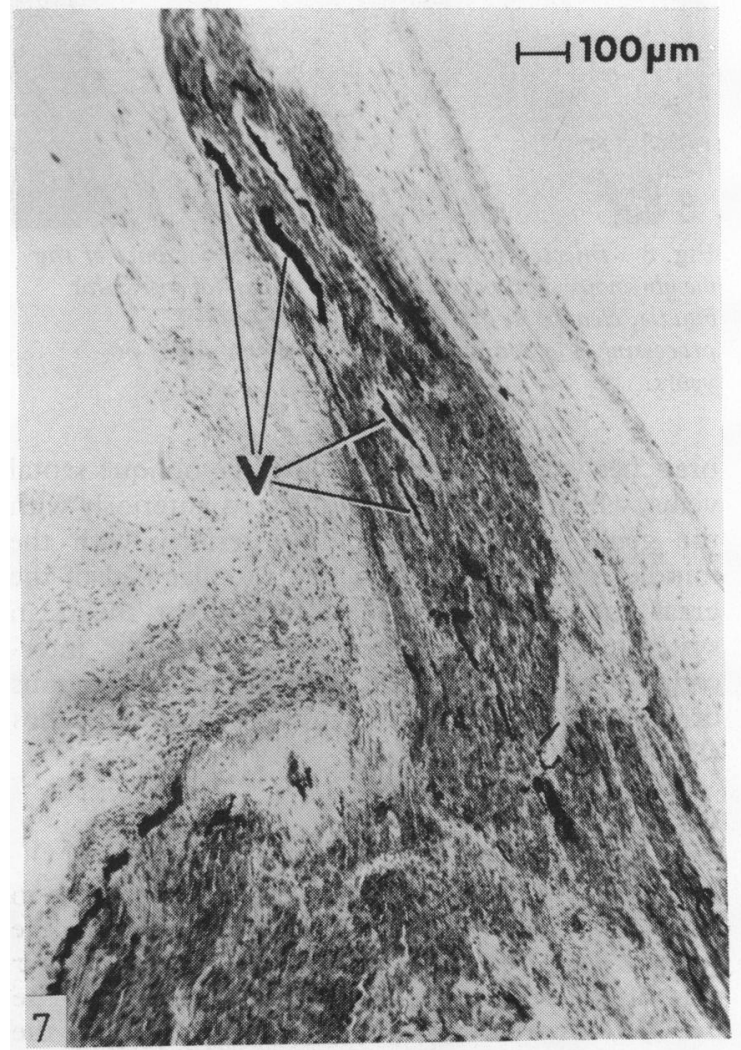

Fig. 7 Veins (V) of the atrioventricular bundle injected with gelatine-solved Indian ink. They pass longitudinally along with the fibres of the conduction system. Haematoxylin and eosin. Woman aged 56 years. 


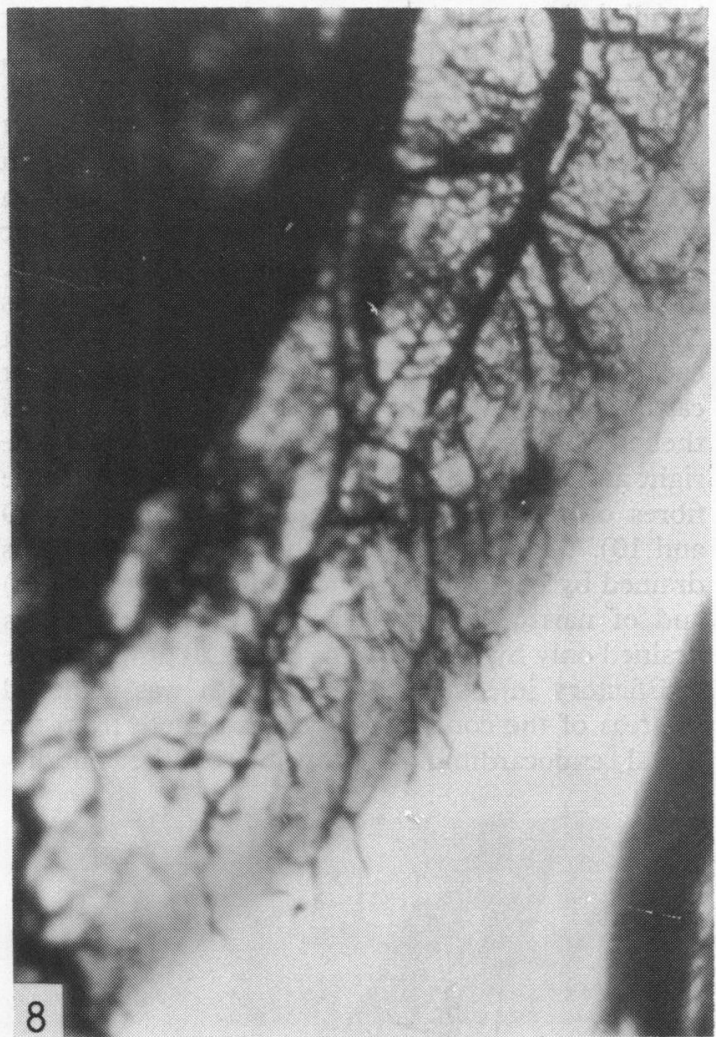

Fig. 8 Injected veins of the upper posterior part of the membranous septum at the site of the atrioventricular bundle, cleared in glycerin before histological processing. Compare with Fig. 7. Woman aged 56 years.

branches were seen to open into the oblique septal veins, which in turn communicated anteriorly with the great cardiac vein and posteriorly with the middle cardiac vein. Since the vascular bed of the great and middle cardiac veins and the thebesian system of the chambers are extensively interconnected, there are many possibilities for venous drainage of the ventricular bundle-branches (Elišková and Eliška, 1969).

\section{Discussion}

The injection of the sinuatrial node allows us to recognise that its venous system drains into the superior vena cava above the node and into the upper part of the atrial appendage below the node. The two systems are extensively interconnected since the Indian ink injected into the opernings of the veins of one group appears in the openings of the other group of veins. Such an anatomical pattern rules out the possibility of venous congestion in the region of the node itself. The upper group of draining veins resembles by its course that of vasa vasorum. In contrast, the lower group of vessels resembles by its course and openings typical thebesian vessels. When adequately injected, the specimens did not show any differences in the density of venous drainage of the conduction system of the sinuatrial node and that of normal myocardium bordering on the node.

Similarly, the veins of the atrioventricular node, the atrioventricular bundle, and its branches also form an extensive anastomotic network. Such a pattern will facilitate venous drainage directly into the right chamber, and into the middle cardiac vein and great cardiac vein. Here again, the venous drainage can be considered nigh on perfect.

Truex and Schwartz (1951), using reconstruction studies, showed that the veins of the atrioventricular bundle formed a sinusoid system most frequently opening into the coronary sinus and into the atrium. These authors thought that toxins in infectious

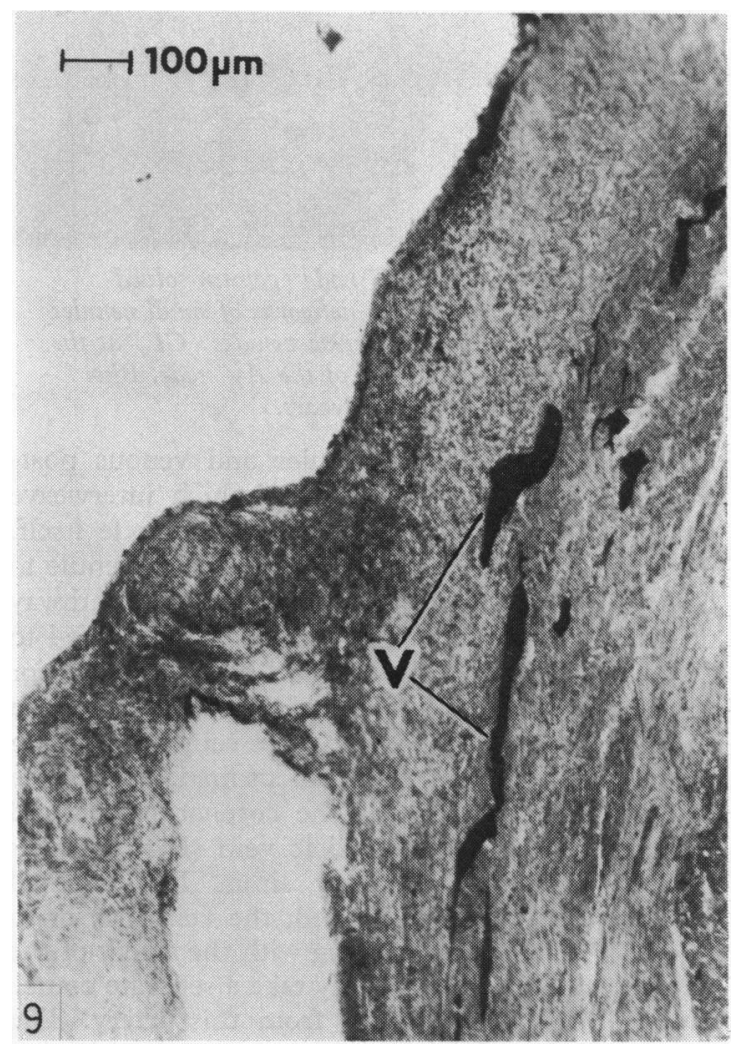

Fig. 9 Wide, longitudinally oriented veins $(V)$ in the upper part of the right bundle-branch at the site of attachment of the septal leaflet of the triscupid valve. Blue trichrome stain. Man aged 30 years, injection with gelatine-solved Indian ink. 


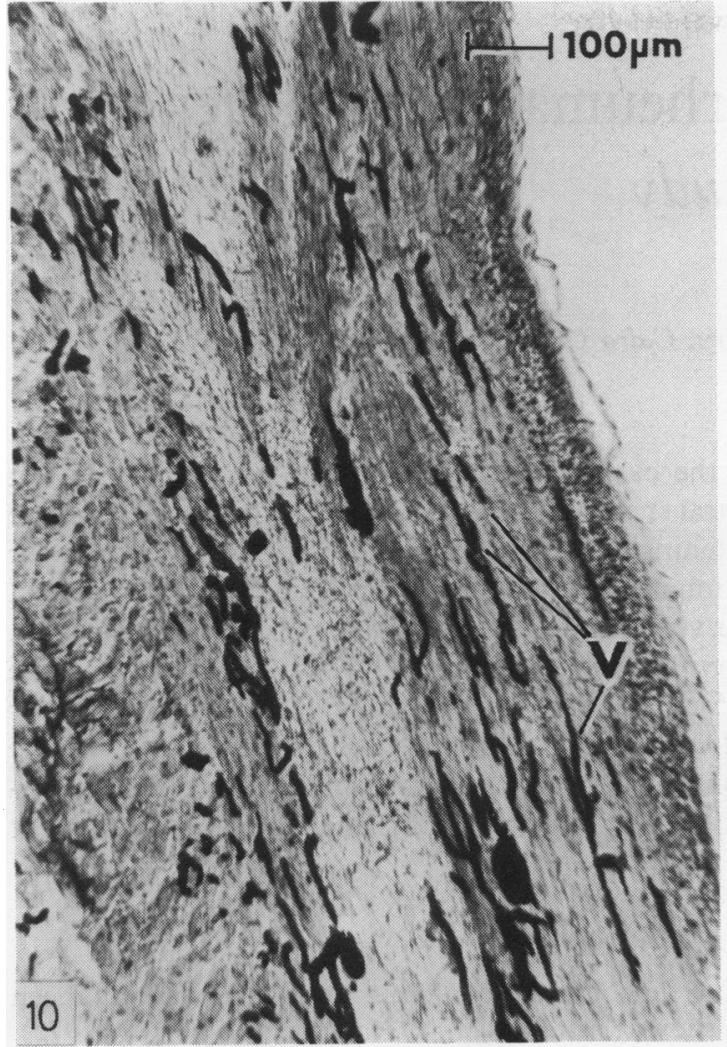

Fig. 10 Longitudinally orientated veins $(V)$ of the left bundle-branch, $1 \mathrm{~cm}$ beyond its origin from the branching bundle. Blue trichrome stain. Man aged 30 years, injection with gelatine-solved Indian ink.

diseases and metabolites in myocardial infarction were capable of influencing the conduction system. Recently, similar conclusions were reached by Davies (1971).

Our preparations allowed us to conclude that the venous drainage of the conduction system was composed of regular postcapillary veins and venules which assumed the appearance of irregular sinusoids in their terminal segments, whence they passed through the atrioventricular node. The course of the larger veins is predominantly longitudinal, parallel with the long axis of the node and the atrioventricular bundle. The cross-sectioned or obliquely sectioned veins seen in histological preparations usually represent tributaries of these longitudinal veins. Lympho-venous anastomoses, such as found in our previous studies (Eliska and Elišková, 1975, 1976), were not encountered in the injected hearts used for the present study.

\section{References}

Abrahám, A. (1964). Die mikroskopische Innervation des Herzens und der Blutgefässe von Vertebraten. Akadémiai Kiadó, Budapest.

Davies, M. J. (1971). Pathology of Conducting Tissue of the Heart. Butterworth, London.

Eliška, O., and Elišková, M. (1975). Contribution to the solution of the question of lymphovenous anastomoses in heart of dog. Lymphology, 8, 11-15.

Eliška, O., and Elišková, M. (1976). Lymph drainage of sinu-atrial node in man and dog. Acta Anatomica, 96, 418-428.

Elił̌ková, M., and Elił̌ka, O. (1969). The septal artery and vein in canine coronary vessels. The blood flow rate through the anterior interventricular vein after ligation of the septal artery. Cor et Vasa, 11, 136-145.

Geraudel, E. (1928). Les veines des cardio-necteurs. Archives des Maladies du Coeur et des Vaisseaux, 21, 149-151.

Kennel, A. J., and Titus, L. J. (1972). The vasculature of the human atrioventricular conduction system. Mayo Clinic Proceedings, 47, 562-566.

Truex, R. C., and Schwartz, M. J. (1951). Venous system of the myocardium with special reference to the conduction system. Circulation, 4, 881-889.

Requests for reprints to Dr O. Eliška, Department of Anatomy, U nemocnice 3, 12800 Prague 2, Czechoslovakia. 